\title{
Interpretation and Modelling of Environmental Behaviour of Diverse Pesticides by Revealing Photodecomposition Mechanisms
}

\author{
Attila Kiss and Diána Virág \\ Eszterházy Károly College, Institute for Food Sciences \\ Hungary
}

\section{Introduction}

Photodecomposition of several organic contaminants involving distinctive pesticides is a topic of high interest for researchers in recent years. Several efforts have recently been made aiming at reduction of potential risks attributed to pesticides, however comprehensive assessment of potential hazards, including characterisation of photodegradates, has been marginally performed (Grover and Cessna, 1991; Burrows et al. 2002). Investigating pesticide degradation occurring in the environment is of high interest as both parent compounds and decomposition products can be hazardous because of their toxicity. Photochemical degradation of pesticides is the breakdown of pesticides by light, particularly sunlight. Photochemical degradation of pesticides can be important in the decontamination of natural water or contaminated soils (Aaron et al., 2001; Coly et al., 1994). Essence of previous studies concerning the examined pesticide is presented as follows.

Atrazine (2-chloro-4-ethylamine-6-isopropylamino-S-triazine) was one of the most popular selective triazine herbicide until it has been classified as a Restricted Use Pesticide (RUP) due to its potential for groundwater contamination (Ware, 1986). It is a photosynthetic inhibitor and used to control broadleaf and grassy weeds. The degradation pathway of the most frequently used triazine pesticide, atrazine, was investigated in aqueous phase by sonolysis, ozonation, photolysis at $254 \mathrm{~nm}$ and photocatalysis in the presence of $\mathrm{TiO}_{2}$ (Bianchi et al., 2006). Dealkylation and dechlorination was induced by ozonation and photocatalysis, while direct photolysis at $254 \mathrm{~nm}$ promoted very efficient dechlorination. Determination of products obtained by photolysis of atrazine in soil samples was performed by Durand and Barcelo (1990, 1991). Hydroxy, 2-H and 2-methoxy derivatives of the parent compound were identified. $\mathrm{TiO}_{2}$ catalysed mineralization of atrazine was also studied along with other triazines (Konstantinou et al. 2001; Parra et al. 2004; Lányi and Dinya, 2005; Pérez et al. 2006). Products formed by oxidation, ring opening, decarboxylation, isomerization, hydroxilation and cyclization were found to be the main degradates. By the loss all of the side chains formation of cyanuric acid and 2-amino-4,6-dihydroxy-1,3,5-s-triazine were observed. The structure of each photolytic degradates (in the presence of porphyrin and phthalocyanine complexes as catalysts) was given by Hequet et al. $(2000,2001)$.

Simazine (6-chloro-N2,N4-diethyl-1,3,5-triazine-2,4-diamine), a wide-spread representative of s-triazine type pesticide, is a selective herbicide with photosynthetic inhibiting effect. It is used 
to control broad-leaved weeds and annual grasses. A comparative study between fragmentation processes taking place in mass spectrometry using an electron ionisation source and photodegradation processes has been carried out for atrazine, simazine and trietazine. The same kinds of fragmentations were observed for the three compounds: $\mathrm{C}-\mathrm{N}$ bond cleavage in the lateral chains, $\mathrm{C}-\mathrm{Cl}$ bond scission and heteroatomic ring cleavage. The photochemical degradation and the kinetics of the degradation processes of s-triazine herbicides (atrazine, propazine, and prometryne) has been investigated in case of several types of natural waters and soils (Konstantinou et al. 2001). The photolytic behaviour of triazine herbicides (atrazine, simazine, trietazine, prometon, prometryn) in the presence of $\mathrm{TiO}_{2}$ as a special photocatalyst has already been studied (Pelizzetti et al., 1990, Hequet et al., 2001). All the herbicides degraded rapidly, full mineralization was not observed. Cyanuric acid was found to be the common final photoproduct of all herbicides. Triazine-derivatives are considered to be the representatives of pesticides of the most wide-spread practical application; therefore it is of crucial importance to evaluate their fate in the environment (Vidal et al. 1999). It was shown that some triazine herbicides undergo photodegradation to form deaminated derivatives (Mansour et al. 1993). The photodegradation products of some commonly used N-containing herbicides were detected however entire mechanisms have not been revealed (Lányi and Dinya, 2005). High-pressure mercury vapour lamp (254 nm, $125 \mathrm{~W}$ ) and GC/MS technique were used during the examinations. Decomposition products steming plausibly from loss of side-chains and substitution with $\mathrm{OH}$-group were detected. Different metabolites formed having mixed side-chains, and the presence of dimer products were also observed.

Acetochlor (2-chloro-N-(ethoxymethyl)-N-(2-ethyl-6-methylphenyl)acetamide), as a member of the chloroacetanilide class of broad leaf herbicides, is one of the most widely used herbicide. It is a growth inhibitor and applied as preemergence for control of annual grasses.

Chloracetanilide herbicides have been investigated the terms of revealing stability, water solubility and toxicity of degradates (Belfroid et al., 1998). Brekken and Brezonik (1998) studied the reaction between acetochlor and HO-, assuming that the primary source of $\mathrm{HO}$ is nitrate photolysis. According to their experimental data, the direct photolysis would be much slower than HO -mediated degradation. In case of acetochlor, serious efforts have been made in order to identify biodegradation products of the pesticide, however no specific reaction pathways have been mapped (Coleman et al., 2000; Thurman et al., 2002; Zheng et al., 2003).

Chlorpyrifos (O,O-diethyl O-(3,5,6-trichloro-2-pyridyl)phosphorothioate) is an organophosphate insecticide, acaricide and miticide used to control foliage and soil-borne insect pests on a variety of food and feed crops. The photodegradation of chlorpyrifos by simulated sunlight in water/methanol has been studied by Barcelo et al. (1993) and 3,5,6trichloro-2-pyridinol was identified as the only degradation product. A method was developed to determine the rate of reaction of chlorpyrifos with $\mathrm{HO}$ radicals in the gas phase at high temperatures during photodecomposition (Hebert et al., 2000). Kamiya and Kameyama (1998) studied the effects of humic materials and metal ions on the photochemical degradation of various organophosphorus pesticides (including chlorpyrifos) (Kamiya et al., 2001).

Carbendazim (methyl benzimidazol-2-ylcarbamate) is a benzimidazole carbamate fungicide with systemic activity and broad effect spectrum. It inhibits fungal mitotic microtubule formation. The visible-light-promoted photodegradation of carbendazim was studied in 
water or water-methanol solution under various conditions (in the presence of air and a photosensitizer xanthene dye or pigment riboflavin, at various $\mathrm{pH}$ values (Escalada et al., 2006, Panades et al., 2000, Mazellier et al., 2002). It was established that the rate of photodegradation increased with $\mathrm{pH}$ and oxygen concentrations. The aqueous photodegradation of carbendazim was studied by Panades et al. (2000). The kinetics of the photodecomposition was determined using HPLC-DAD and the identification of photoproducts was carried out with HPLC-MS by Boudina et al., (2003). Three products were detected after the UV irradiation. One of them, 2,4-amino-benzimidazol has already been identified in a previous paper (Mallat et al, 1997, Tomlin, 1994). A plausible pathway for the photolytic degradation of carbendazim in pure water was proposed as well, however our studies pointed out marked differences when comparing the two different mechanisms.

Diuron (N-(3,4-dichlorophenyl)-N,N-dimethyl urea) is a substituted urea type nonselective herbicide with photosynthesis inhibition effect (Wessels and Veen, 1956). Its principal breakdown product 3,4-dichloroaniline is more toxic than diuron itself. It is persistent and contaminates marine waters, groundwater, sediment and soil (Giacomazzi and Cochet, 2004). It is considered as a Priority Hazardous Substance by the European Commission (Mehlhorn, 2001).

EPTC (S-ethyl dipropylthiocarbamate) is a selective, growth inhibitor herbicide of thiocarbamate-type. The UV-photodegradation of EPTC in hexane has been studied by Marco and Hayes (1979) as well as Abu-Qare et al. (2002). Formation of several photoproducts and the cleavage of C-S and C-N bonds were observed but no reaction pathway was revealed. The kinetics of photodegradation of EPTC was studied by Dinya and Lányi (2005.).

In summary it might be stated that huge efforts have been made to characterise both the chemical and environmental behaviour of pesticides, however the precise reaction mechanisms of photodegradation have not been revealed, and in some cases controversial results have been obtained. Hence identification of major degradates might be considered as a major task in order to gain insight into the photodegradation and environmental behaviour of the selected and investigated pesticides.

The abovementioned information shows that numerous photodegradation studies have been performed especially concerning s-triazines. However, with the exception of atrazine, detailed reaction mechanisms of the concerned pesticides have not been identified. In some cases, specific degradation products were detected without the aim of mapping the entire pathway of photodegradation. Thus our work contributes to a more extensive and comprehensive knowledge on pesticide photodecomposition with regard to both reaction mechanism and chemical characteristics of degradation products. The pathway of photolytic degradation of seven pesticides having diverse chemical structure and practical application is mapped by GC/MS identification of degradation products.

\section{Specified results}

\subsection{Photodegradation of ATRAZINE}

The five-hour-long UV-irradiation of atrazine [2-chloro-4-ethylamine-6-isopropylamino-Striazine] resulted in the cleavage of the chloro-group and the hydroxylation of the ring. As a consequence [1,3,5-triazin-2-hydroxy-4-(ethylamino)-6-(isopropyl)amino] could be detected. [1,3,5-triazin-2-hydroxy-4,6-(diethylamino)] was generated by the scission of a methyl- 
group. [1,3,5-triazin-2-hydroxy-4,6-diamine] might be identified as the end product of the photodegradation by consecutive de-ethylation processes.

Novelty: In contrast to other studies 20-hour-long UV-irradiation did not lead to the formation of cyanuric acid as the end-product. Under natural conditions this compound is not likely to be formed; it could only be obtained by $\mathrm{TiO}_{2} / \mathrm{Na}_{2} \mathrm{~S}_{2} \mathrm{O}_{8}$ catalyzed degradation (Lányi and Dinya, 2005, Pérez et al. 2006). In comparison with the results of previous studies it might be established that dechlorination, hydroxylation and scission of methyl- and ethyl groups are regarded as major steps of the photodegradation of atrazine. Ring opening, dimerisation and decarboxylation were not detected during our studies.

\subsection{Photodegradation of SIMAZINE}

The degradation of simazine [2,6-di(ethylamino)-4-chloro-1,3,5-triazine] effected by UVphotons can take place via two parallel reaction pathways. Major steps of the photodecomposition were found to be as follows: cleavage of a chloro-group and its partial substitution to OH-group, loss of methyl and ethyl groups, and scissoring of OH-group. The most stabile degradation product of simazine is [2,4-di(ethylamino)-1,3,5-triazine].

Novelty: In contrast with the finding of Pelizzetti, and identification of cyanuric acid, symmetrical [2,4-diamino-1,3,5-triazine] was obtained by us as the end-product of the degradation of the triazine-type pesticide. Studies aiming at investigating the photolytic degradation of simazine so far have only pointed out the fact of degradation and the factors influencing it (Mansour et al. 1993, Hequet et al., 2001, Bianchi et al., 2006). Previously efforts were made to propose a reaction pathway for the decomposition (Pelizzetti et al., 1990), and to detect the loss of side-chains and their substitution with OH-group (Lányi et al., 2005), however identification of all the major degradates ([2,4-di(ethylamino)-hydroxy1,3,5-triazine], [2-amino-4-chloro-6-methylamino-1,3,5-triazine], [2-ethylamino-4methylamino-1,3,5-triazine], [2-amino-4-methylamino-1,3,5-triazine]) and revealing the complete decomposition pathway might be regarded as new findings.

\subsection{Photodegradation of ACETOCHLOR}

In case of the photodegradation of acetochlor [2-chloro-N-(ethoxymethyl)-N-(2-ethyl-6methylphenyl)acetamide] there are alternative reaction pathways according to our findings. Several degradation products could be detected after some hours of irradiation: [2-chloro-Nhydroximethyl-N-(2-ethyl-6-methylphenyl)acetamide], [N-hydroximethyl-N-(2-ethyl-6methylphenyl)acetamide], [N-methyl-N-(2-ethyl-6-methylphenyl)acetamide]. Major steps of photodecomposition are as follows: cleavage of ester-bond of N-ethoxy-methyl group, breaking off the chloro- and the hydroxyl-groups, resulting in the formation of [2-ethyl-6methyl-N-methyl-aniline]. This last degradation product might be formed from the parent compound in a direct way as well. Alternatively, the cleavage of chloro-, methyl- and ethoxy-groups of the parent compound and the production of a formanilid-derivative [Nmethyl-N-(2-ethyl-6-methylphenyl)formamide] might also be observed. Cleavage of methyl, ethyl and amino-groups, through the formation of [2-ethyl-6-methyl-aniline] led to the formation of [3-ethyl-toluene] as an end product.

Novelty: Three main degradation products of acteochlor we detected were also determined by other studies aiming at modelling biodegradation of acetochlor, but the total degradation pathway of acetochlor has not been revealed so far. The biological degradation of acetochlor led to the formation of metabolites being not analogous to intermediers detected during our investigations (Coleman et al., 2000; Zheng et al., 2003). The determination of all 9 
degradation products and mapping the entire degradation pathway by our experiments contributes to the entire understanding of acetochlor's environmental behaviour.

\subsection{Photodegradation of chlorpyrifos}

The photodegradation of chlorpyrifos [O,O-diethyl-O-(3,5,6-trichloro-2pyridyl)phosphorothioate] may occur via two reaction patterns. It might be initiated by the cleavage of either an ethyl-group or a chloro-group resulting in the formation of [O-ethyl-O(3,5,6-trichloro-2-pyridil)-hydrogene- phosphorothioate] and [O,O-diethyl-O-(3,5-dichloro-2pyridil)phosphorothioate]. The following step of the decomposition is the scission of chloro and ethyl groups ([O-ethyl-O-(3,5-dichloro-2-pyridil)-hydrogene-phosphorothioate]). Breaking away of another chloro-group leads to the formation of [O-ethyl-O-(5-chloro-2-pyridil)hydrogene- phosphorothioate]. Loss of the other ethyl-group transforms the previous compound into the end-product [O-(5-chloro-2-pyridil)-dihydrogene-phosphorothioate], whose presence is shown in the GC-chromatogram and the mass spectrums.

Novelty: Neither the detected and identified UV-induced degradation products of chlorpyrifos, nor its degradation pathway has not been described and observed so far. These degradates are not analogous with the results of Barcelo (1993) and Xu (2008): only 3,5,6trichloro-2-pyridinol was found as the product of the biological degradation of chlorpyrifos by a newly isolated Paracoccus sp. strain TRP.

\subsection{Photodegradation of carbendazim}

The first step of the degradation of carbendazim [methyl-benzimidazole-2-ylcarbamate] was the loss of the methyl group and the formation of [benzimidazole-2-ylcarbamic-acide], which product showed small stability, and subsequent to the cleavage of a hydroxyl- and a carbonyl group the origination of [benzimidazole-2-ylcarbamate] was observed. This product was transformed into [2-amino-benzimidazole] which was converted to the rather stabile benzimidazole by deamination as a result of further UV-treatment. Several hours of following UV-irradiation led to opening of the imidazole-ring and to the production of [2methyl-amino-aniline]. Subsequently, by the cleavage of the $\mathrm{N}$-methyl bond the endproduct of the photodegradation, [1,2-diaminobenzene] was acquired.

Novelty: Formation of 2,4-amino-benzimidazole, benzene, phenol or aniline, or any dimmer products was not observed in our studies, contrary to the findings of Mallat et al., Mazellier et al. and Tomlin.

\subsection{Photodegradation of DIURON}

The photocatalytic degradation of diuron [N-(3,4-dichlorophenyl)-N,N-dimethyl urea] was easy to be initiated. The main degradation products could already be detected just after 2 hours of UV-irradiation. By the scission of the N-dimethyl group [N-4,5-dichloro-phenylisocyanate] was formed. Dechlorination processes were also observed generating [Ndichloro-phenyl-isocyanate] and [benzene-isocyanate]. An alternative reaction pathway may also occur: dechlorination of the parent compound led to the formation of [N,N-dimethyl$\mathrm{N}^{\prime}$-phenylurea]. The loss of $\mathrm{N}$-dimethyl group and the incorporation of a propyl-group yielded [N-(4-isopropyl-phenyl)-formamide] as an intermedier of the photolytic decomposition. Decarbonylation was induced by further UV-irradiation and [aniline] was detected as the end product of the photodegradation of diuron. [2-methyl-propinic acid] was produced as a secondary- or by-product of the degradation processes. 
Novelty: The degradation mechanism of diuron was not thoroughly investigated yet prior to our studies. The main steps of phototransformation were found to be the sequential cleavage of the chloro-group and the $\mathrm{N}$-dimethyl-group, as well as hydroxylation and dehydroxylation processes.

\subsection{Photodegradation of EPTC}

Photochemical decomposition of EPTC [S-ethyl-dipropyl-thiocarbamate] occurs rapidly as the appearance of the first degradation product could already be detected subsequent to twenty-minute-long UV-irradiation. During the photochemical degradation of EPTC [N,Ndipropyl-formamide] and [N,N-diethyl-propionamide] are formed at the first stage of the transformation via two alternative decomposition routes. Both the cleavage of S-ethyl-group and the demethylation of $\mathrm{N}$-propyl groups are possible. In accordance with the given reaction pathways it might be established that both the consecutive losses of alkyl-groups and the cleavage of the amide bond lead to the degradation end-product: [diethyl-amine]. Some other degradates were also identified, such as: [tripropylamine], [dipropylamine], [dipropyl-ethyl-amine].

Novelty: When comparing findings of our studies with previous research on revealing products of biological degradation of EPTC (Abu-Qare and Duncan, 2002) it might be established that photodecomposition and biological degradation do not result in the formation of analogous products, as nor EPTC-sulfon or EPTC-sulphoxide were detected throughout our examinations. Breaking off of S- and N-alkyl groups resulted in the same degradates as identified previously, however ketoformyl and ketocarbonyl derivatives might only be observed in $\mathrm{TiO}_{2}$ catalytized photodegradation processes (Lányi and Dinya, 2005).

\section{Summary}

Our study is focused on revealing specific details of photolytic degradation of pesticides whose decomposition mechanisms have not been mapped entirely yet. Importance of the study is enhanced by the fact that scarce information is available regarding their natural degradation processes, as well as the quality, structure and biological impact of the decomposition products.

In order to clarify the photolytic decomposition behaviour of selected pesticides and to be capable of right interpretation of the complete mechanisms, our major goal was to isolate and identify the degradation products by applying GC-MS and HPLC-MS techniques. Subsequently the most plausible degradation pathways were established, and the rate of the photodecomposition was also followed. Frequently applied pesticides of distinctive chemical structure and physical behaviour have been selected for our studies. Our study presents the total mechanisms of the photoinduced degradation of various pesticides in case of acetochlor, simazine, chlorpyrifos, carbendazim (Kiss and Virág, 2009/a) and diuron, atrazine, and EPTC (Kiss and Virág, 2009/b).

\section{References}

Aaron, J.J., and M.A. Oturan. 2001. New photochemical and electrochemical methods for the degradation of pesticides in aqueous media. Environmental applications.Turk. J. Chem. 25:509-520. 
Abu-Qare, A. W., H. J. Duncan, Photodegradation of the herbicide EPTC and the safener dichlormid, alone and in combination. Chemosph. 46 (2002) 1183-1189.

Barcelo, D., G. Durand, and N.D. Bertrand. 1993. Photodegradation of the organophosphorus pesticides chlorpyrifos, fenamiphos and vamidothion in water. Toxicol. Environ. Chem. 38:183-199.

Belfroid A.C., M. van Drunen, M.A. Beek, S.M. Schrap, C.A.M. van Gestel, and B. van Hattum. 1998. Relative risks of transformation products of pesticides for aquatic ecosystems.Sci. Total. Environ. 222:167 -183.

Brekken, J.F., and P.L. Brezonik. 1998. Indirect photolysis of acetochlor: Rate constant of a nitrate-mediated hydroxyl radical reaction. Chemosphere 36:2699-2704.

Bianchi, C. L., C. Pirola, V. Ragaini, and E. Selli. 2006. Mechanism and efficiency of atrazine degradation under combined oxidation processes. Applied Catalysis B: Environmental 64:131-138.

Boudina, A., C. Emmelin, A. Baaliouamer, M. F. Grenier-Loustalot, and J. M. Chovelon. 2003. Photochemical behaviour of carbendazim in aqueous solution. Chemosph. 50:649-655

Burrows, H.D., L.M. Canle, J.A. Santaballa, S. Steenken, Reaction pathways and mechanisms of photodegradation of pesticides. J. Photochem. Photobiol. B: 67 (2002) 71-108.

Coleman, S., R. Linderman, E. Hodgson, and R.L Rose. 2000. Comparative metabolism of chloroacetamide herbicides and selected metabolites in human and rat liver microsomes. Environ. Health. Perspect. 108: 1151-1157.

Coly, A., and Aaron, J. J. 1994. Fluorimetric determination of aromatic persticides in technical formulations. Effects of solvent and of ultraviolet photolysis. Talanta 41:1475-1480.

Durand, G., D. Barceló, Determination of chlorotriazines and their photolysis products by liquid chromatography with photodiode-array and thermospray mass spectrometric detection. J. Chromatography A. 502 (1990) 275-286.

Durand, G., D. Barceló, Confirmation of chlorotriazine pesticides, their degradation products and organophosphorus pesticides in soil samples using gas chromatography-mass spectrometry with electron impact and positive- and negative-ion chemical ionization. Anal. Chim. Acta, 243 (1991) 259-271.

Escalada, J. P., A. Pajares, J. Gianotti, W.A. Massad, S. Bertolotti, F. Amat-Guerri, and N.A. García. 2006. Dye-sensitized photodegradation of the fungicide carbendazim and related benzimidazoles. Chemosphere 65:237-244.

Giacomazzi, S., N. Cochet, Environmental impact of diuron transformation: a review Chemosph.56 (2004) 1021-1032.

Grover, R., A.J. Cessna, (Eds.), Environmental Chemistry of Herbicides, CRC Press, Boca Raton, 1991.

Hebert, V.R., C. Hoonhout, and G.C. Miller. 2000. Use of stable tracer studies to evaluate pesticide photolysis at elevated temperatures. J. Agric. Food Chem. 48:1916-1921.

Hequet, V., P. Cloirec, C. Gonzalez, B. Meunier, Photocatalytic degradation of atrazine by porphyrin and phthalocyanine complexes. Chemosph. 41 (2000) 379-386.

Hequet, V., C. Gonzalez, P. Cloirec, Photochemical processes for atrazine degradation: methodological approach. Water Research, 35 (2001) 4253-4260.

Kamiya, M., and K. Kameyama. 1998. Photochemical effects of humic substances on the degradation of organophosphorus pesticides. Chemosphere 36:2337-2344.

Kamiya, M., K. Kameyama, S. Ishiwata. 2001. Effects of cyclodextrins on photodegradation of organophosphorus pesticides in humic water. Chemosphere 42:251-255.

Kiss, A., D. Virág, Photostability and photodegradation pathways of distinctive pesticides. J. Environ. Qual. 38 (2009/a) 1. 
Kiss, A., D. Virág, Interpretation and modelling of environmental behaviour of diverse pesticides by revealing photodecomposition mechanisms. Microchemical Journal. (2009/b) 92(2)119-122

Konstantinou, I.K., A.K. Zarkadis, T.A. Albanis, Photodegradation of selected herbicides in various natural waters and soils under environmental conditions. J. Environm. Qual. 30 (2001) 121-130.

Lányi, K., Z. Dinya, Photodegradation study for assessing the environmental fate of some triazine-, urea- and thiolcarbamate-type herbicides. Microchem. J. 80 (2005) 79-87.

Mallat, E., D. Barcelo, and R. Tauler 1997. Degradation study of benomyl and carbendazim in water by liquid chromatography and multivariate curve resolution methods. Chromatographia 46:342-350.

Mansour, M. Ed. 1993. Fate and Prediction of Enviromental Chemicals in Soils, Plants and Aquatic Systems. Lewis, Boca Raton, Ann Arbor, USA.

Marco, A.C.D., E.R. Hayes, Photodegradation of thiolcarbamate herbicides. Chemosph 1 (1979) 321-326.

Mazellier, P. É. Leroy, and B. Legube. 2002. Photochemical behavior of the fungicide carbendazim in dilute aqueous solution. J. Photochem. Photobiol. A: Chemistry; 153:221-227.

Mehlhorn, B., The EU-list of priority substances - a new strategy against water pollution. (No. 2477/2001/EC) Annex X of Water Framework Directive (2000/60/EC). 2001, Umweltbundesamt, Berlin.

Panadés, R., A. Ibarz, and S. Esplugas. 2000. Photodecomposition of carbendazim in aqueous solutions. Water Res 34:2951-2954.

Parra, S., S.E. Stanca, I.K. Guasaquillo, R. Thampi, Photocatalytic degradation of atrazine using suspended and supported $\mathrm{TiO}_{2}$. Appl. Cat. B: Environm. 51 (2004) 107-116.

Pelizzetti, E., V. Maurino, C. Minero, V. Carlin, E. Pramauro, O. Zerbinat, and M.L. Tosato. 1990. Photocatalytic degradation of atrazine and other s-triazine herbicides. Environ. Sci. Technol. 24:1559-1565.

Pérez, M.H., G. Peñuela, M.I. Maldonado, O. Malato, P. Fernández-Ibáñez, I. Oller, W. Gernjak, S. Malato, Degradation of pesticides in water using solar advanced oxidation processes. Appl. Cat. B: Environm. 64 (2006) 272-281.

Thurman, E.M., I. Ferrer, and R. Parry 2002. Accurate mass analysis of ethanesulfonic acid degradates of acetochlor and alachlor using high-performance liquid chromatography and time-of-flight mass spectrometry. J. Chromatogr. A 957:3-9.

Tomlin. 1994. The Pesticide Manual., Tomlin Crop Protection Publications, Cambridge United Kingdom.

Zheng H.H., and C.M. Ye. 2003. Photodegradation of acetochlor in water and UV photoproducts identified by mass spectrometry. J. Environ. Sci.-China 15:783-790.

Vidal, A., Z. Dinya, and F. Mogyoródi. 1999. Photocatalytic Degradation of Thiocarbamate Herbicide Active Ingredients in Water. Appl. Catal. B: Environ. 21:259-267.

Ware, G.W., Fundamentals of Pesticides: A Self-Instruction Guide, 2nd Edition. Thomson Publications (Eds.), Fresno, CA, 1986, pp. 8-3.

Wessels, J.S.C., R. van der Veen, The action of some derivatives of phenylurethan and of 3,phenyl-1,1-dimethylurea on Hill reaction. Biochem. Biophys. Acta 19 (1956) 548549 .

Xu, G., W. Zheng, Y. Li, S. Wang, J. Zhang and Y. Yan. 2008. Biodegradation of chlorpyrifos and 3,5,6-trichloro-2-pyridinol by a newly isolated Paracoccus sp. strain TRP. International Biodeterioration \& Biodegradation In Press, Corrected Proof 


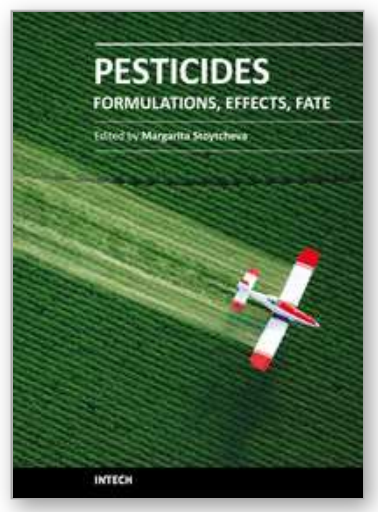

\author{
Pesticides - Formulations, Effects, Fate \\ Edited by Prof. Margarita Stoytcheva
}

ISBN 978-953-307-532-7

Hard cover, 808 pages

Publisher InTech

Published online 21, January, 2011

Published in print edition January, 2011

This book provides an overview on a large variety of pesticide-related topics, organized in three sections. The first part is dedicated to the "safer" pesticides derived from natural materials, the design and the optimization of pesticides formulations, and the techniques for pesticides application. The second part is intended to demonstrate the agricultural products, environmental and biota pesticides contamination and the impacts of the pesticides presence on the ecosystems. The third part presents current investigations of the naturally occurring pesticides degradation phenomena, the environmental effects of the break down products, and different approaches to pesticides residues treatment. Written by leading experts in their respective areas, the book is highly recommended to the professionals, interested in pesticides issues.

\title{
How to reference
}

In order to correctly reference this scholarly work, feel free to copy and paste the following:

Attila Kiss and Diána Virág (2011). Interpretation and Modelling of Environmental Behaviour of Diverse Pesticides by Revealing Photodecomposition Mechanisms, Pesticides - Formulations, Effects, Fate, Prof. Margarita Stoytcheva (Ed.), ISBN: 978-953-307-532-7, InTech, Available from:

http://www.intechopen.com/books/pesticides-formulations-effects-fate/interpretation-and-modelling-ofenvironmental-behaviour-of-diverse-pesticides-by-revealing-photodeco

\section{INTECH}

open science | open minds

\author{
InTech Europe \\ University Campus STeP Ri \\ Slavka Krautzeka 83/A \\ 51000 Rijeka, Croatia \\ Phone: +385 (51) 770447 \\ Fax: +385 (51) 686166 \\ www.intechopen.com
}

\author{
InTech China \\ Unit 405, Office Block, Hotel Equatorial Shanghai \\ No.65, Yan An Road (West), Shanghai, 200040, China \\ 中国上海市延安西路65号上海国际贵都大饭店办公楼 405 单元 \\ Phone: +86-21-62489820 \\ Fax: +86-21-62489821
}


(C) 2011 The Author(s). Licensee IntechOpen. This chapter is distributed under the terms of the Creative Commons Attribution-NonCommercialShareAlike-3.0 License, which permits use, distribution and reproduction for non-commercial purposes, provided the original is properly cited and derivative works building on this content are distributed under the same license. 